\title{
The role of Scheimpflug imaging in the management of posterior scleritis
}

\author{
This article was published in the following Dove Press journal: \\ Eye and Brain \\ 18 May 2010 \\ Number of times this article has been viewed
}

\author{
Natalia Pawlowska \\ Jonathan Luck \\ Department of Ophthalmology, \\ The Royal United Hospital, \\ Bath, UK
}

Correspondence: Natalia Pawlowska Department of Ophthalmology, The Royal United Hospital, Combe Park, Bath BAI 3NG, UK

Tel +44I 225824767

Fax +44I $225824 \mid 42$

Email natpawl@googlemail.com

\begin{abstract}
Posterior scleritis is a rare but sight-threatening ocular inflammatory disorder that can present in a number of different ways and sometimes silently. Diagnosis can be difficult, and usually is clinical, confirmed by B-mode ultrasonography. Patients can be at risk of angleclosure glaucoma in this condition, and traditional methods of angle assessment can be subjective and difficult to perform in the inflamed eye. We present a case of posterior scleritis where management was aided by the use of a Scheimpflug imaging device.
\end{abstract}

Keywords: posterior scleritis, Scheimpflug, Pentacam

\section{Introduction}

Posterior scleritis is a rare inflammatory condition affecting the sclera behind the equator of the globe. It can coexist with anterior scleritis or be isolated, in which case diagnosis can be difficult. The clinical features can be nonspecific, and confused with those of generalized intraocular or orbital inflammation. ${ }^{1}$

Angle-closure glaucoma may occur in posterior scleritis, usually as a result of uveal effusion. ${ }^{2,3}$ Scheimpflug imaging of the anterior segment is an accurate method of analysing the anterior segment of the eye, including the configuration of the angle and anterior chamber depth. We report a case of a 70-year-old gentleman with posterior scleritis for whom the use of Scheimpflug imaging (Pentacam; Oculus Optikgeräte $\mathrm{GmbH}$, Wetzlar, Germany) proved valuable in the diagnosis, monitoring of response to treatment, and relapse detection.

\section{Case report}

A 70-year-old male presented to the accident and emergency department at our institution with a five-day history of pain and redness in his right eye. Past medical history only included gastroesophageal reflux and bladder obstruction. Examination revealed conjunctival injection in isolation. There were no other obvious physical signs. Visual acuity was $6 / 6$ in the right eye and $6 / 5$ in the left. Intraocular pressure (IOP) was normal in both eyes. He was treated as a case of episcleritis with Indomethacin $50 \mathrm{mg}$ three times daily (TDS) (MSD, Hoddesdon, UK) and gutt. fluorometholone four times daily (QDS) (Allergan, Buckinghamshire, UK). Symptoms initially resolved, but over the next few weeks, he attended the general eye clinic on four more occasions with varying degrees of redness and pain in his right eye. Eventually two months after the initial presentation he attended the Acute Eye Clinic with severe recurrence of his symptoms. Visual acuities remained normal at 6/6 OD and 6/5 OS as previously.

submit your manuscript | www.dovepress.com 
Table I Anterior chamber parameters during acute angle closure associated with posterior scleritis

\begin{tabular}{lll}
\hline & Right & Left \\
\hline Anterior chamber angle (degrees) & 18.9 & 27 \\
Anterior chamber volume $\left(\mathrm{mm}^{3}\right)$ & 56 & 114 \\
Anterior chamber depth $(\mathrm{mm})$ & $1.5 \mathrm{I}$ & 2.19 \\
\hline
\end{tabular}

On slit-lamp examination, an asymmetrically shallow anterior chamber in the right eye and IOP of 42 was documented. A B-mode ultrasound scan showed typical changes consistent with posterior scleritis. Scheimpflug imaging (Pentacam; Oculus Optikgeräte $\mathrm{GmbH}$ ) confirmed and quantified a very shallow anterior chamber in the right eye (Figure 1, Table 1). He was treated with $40 \mathrm{mg}$ of oral prednisolone (generic) together with a mucosal protectant, and then the prednisolone was carefully tapered over three weeks. The IOP quickly reduced to normal.

Scheimpflug imaging scan performed one month later confirmed improved parameters of the anterior chamber (Figure 2, Table 2).

The patient is currently on $5 \mathrm{mg}$ prednisolone daily.
Table 2 Anterior chamber parameters one month after initiation of treatment with systemic corticosteroids

\begin{tabular}{lll}
\hline & Right & Left \\
\hline Anterior chamber angle (degrees) & 25 & 26 \\
Anterior chamber volume $\left(\mathrm{mm}^{3}\right)$ & 112 & 114 \\
Anterior chamber depth $(\mathrm{mm})$ & 2.07 & 2.19 \\
\hline
\end{tabular}

\section{Discussion}

Posterior scleritis is a rare condition that can easily be missed, and can frequently lead to vision threatening complications. It can be idiopathic, or associated with systemic vasculitides, such as Wegener's granulomatosis. A systemic association exists in $30 \%$ of cases. ${ }^{4}$ Posterior scleritis can be asymptomatic, but symptoms can include pain (especially on eye movement) photophobia, and blurred vision. Signs can include associated anterior scleritis, exudative retinal detachment, ${ }^{5}$ optic disc swelling, subretinal granulomata formation, elevated IOP, choroidal effusion, ${ }^{6}$ uveitis, and retinal vasculitis. In a large retrospective study, no abnormalities were present in $17 \%$ of those who had a final diagnosis of posterior scleritis, and visual loss can occur in up to $30 \%$ of patients. ${ }^{4}$

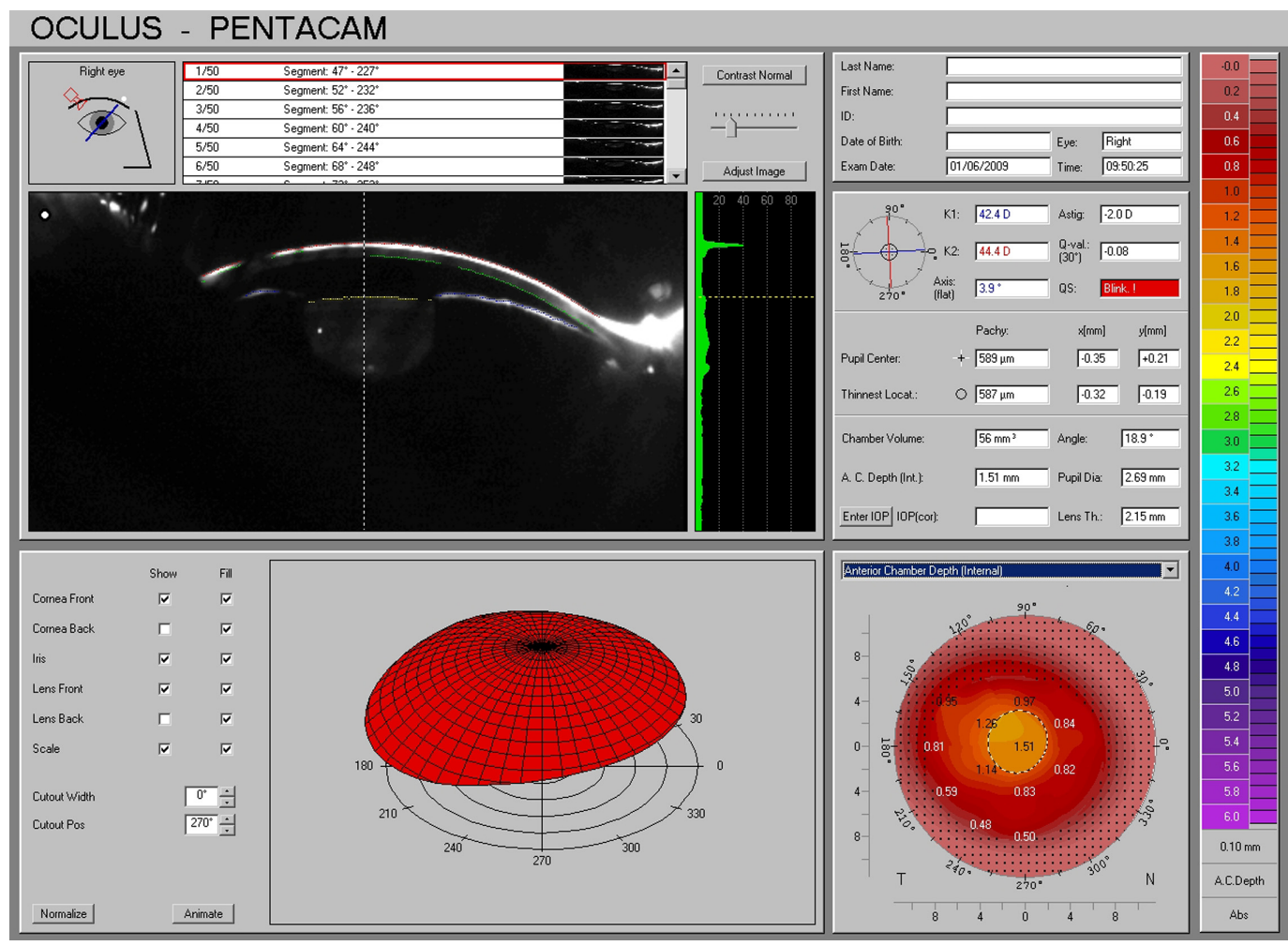

Figure I Pentacam imaging performed at acute presentation. The raw Scheimpflug slit image is shown together with anterior chamber depth in the lower right of the image. The red domed image at center bottom is a $3 \mathrm{D}$ anterior chamber reconstruction. 


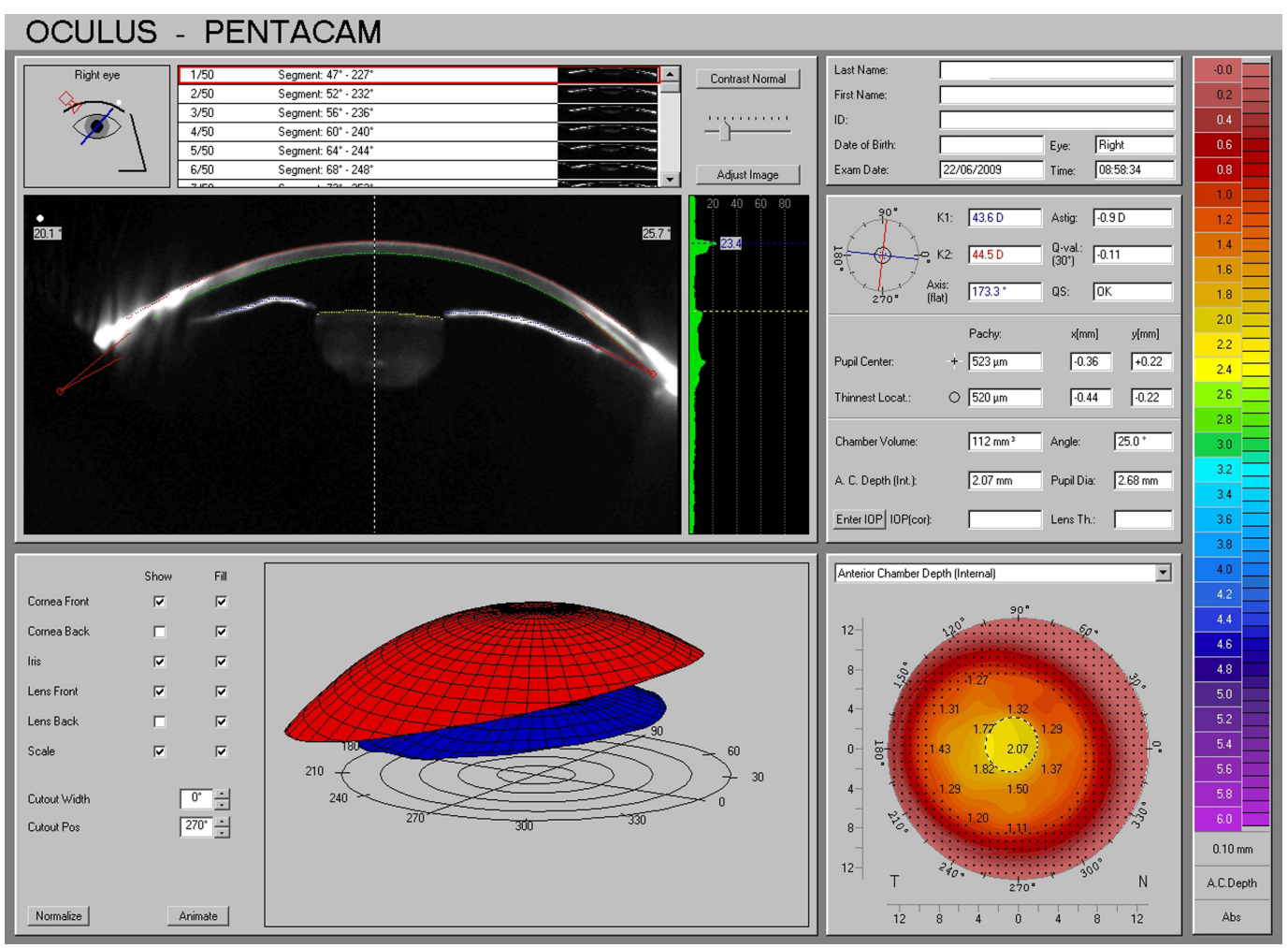

Figure 2 Pentacam imaging performed one month after initiation of treatment with systemic corticosteroids. The central anterior chamber depth has increased significantly from $1.51 \mathrm{~mm}$ to $2.07 \mathrm{~mm}$.

The mainstay of diagnosis is B-mode ultrasonography. Characteristic ultrasonographic findings include fluid in the subtenon space and posterior scleral thickening. ${ }^{7}$ This can also be demonstrated by computed tomography and magnetic resonance imaging. ${ }^{8}$

A common complication is increased IOP and angle closure. It can be caused by inflammatory cells blocking the scleral emissary vessels leading to increased episcleral venous pressure. Ciliary body detachment adjacent to the inflammation can cause angle closure by shifting the lensiris diaphragm, and uveal effusion can contribute to the angle-closure mechanism. Associated uveitis can lead to the trabecular meshwork being clogged with inflammatory cells, with an associated rise in IOP. A topical steroid pressure response can add to the pressure rise. Gonioscopy is a traditional method of assessing the anterior chamber angle, but it is highly subjective and can be very uncomfortable for the patient with an inflamed eye. Scheimpflug imaging is a relatively new way of accurately assessing and quantifying anterior chamber parameters. It can accurately and reproducibly measure the anterior chamber angle, anterior chamber depth across the entire anterior segment, and measure anterior chamber volume. ${ }^{9}$
In this case, the Scheimpflug camera was very useful in the assessment of the anterior chamber, and confirmed the clinical impression of asymmetric anterior chamber shallowing and threatened angle closure. This increased the clinical suspicion of posterior scleritis, and proved extremely useful in measuring and monitoring the clinical response to treatment. Although there are other causes of asymmetric anterior chamber shallowing, we suggest that Scheimpflug imaging could be useful in patients with a clinical and ultrasonographic suspicion of posterior scleritis. This cannot only assist in the sometimes difficult diagnostic process, but also can be useful in monitoring anterior chamber parameters to help predict threatened angle closure glaucoma and to monitor the response to treatment of this sight-threatening condition.

\section{Disclosures}

The authors declare no conflicts of interest.

\section{References}

1. Rubinstein A, Riddell CE. Posterior scleritis mimicking orbital cellulitis. Eye (Lond). 2005;19(11):1232-1233.

2. Quinlan MP, Hitchings RA. Angle-closure glaucoma secondary to posterior scleritis. Br J Ophthalmol. 1978;62(5):330-335. 
3. Jain SS, Rao P, Kothari K, Bhatt D, Jain S. Posterior scleritis presenting as unilateral secondary angle-closure glaucoma. Indian J Ophthalmol. 2004;52(3):241-244.

4. McCluskey PJ, Watson PG, Lightman S, Haybittle J, Restori M, Branley M. Posterior scleritis: clinical features, systemic associations, and outcome in a large series of patients. Ophthalmology. 1999;106(12): 2380-2386.

5. Leitch RJ, Bearn MA, Watson PG. Exudative retinal detachment and posterior scleritis associated with massive scleral thickening and calcification treated by scleral decompression. Br J Ophthalmol. 1992;76(2):109-112.
6. Marushak D. Uveal effusion attending scleritis posterior. A case report with A-scan and B-scan echograms. Acta Ophthalmol (Copenh). 1982;60(5):773-778.

7. Rochels R, Reis G. [Echography in posterior scleritis (author's transl)]. Klin Monatsbl Augenheilkd. 1980;177(5):611-613.

8. Chaques VJ, Lam S, Tessler HH, Mafee MF. Computed tomography and magnetic resonance imaging in the diagnosis of posterior scleritis. Ann Ophthalmol. 1993;25(3):89-94.

9. Dinc U, Oncel B, Gorgun E, Alimgil L. Quantitative assessment of anterior chamber volume using slit-lamp OCT and Pentacam. Eur J Ophthalmol. 2009;19(3):411-415.
Eye and Brain

\section{Publish your work in this journal}

Eye and Brain is an international, peer-reviewed, open access journal focusing on clinical and experimental research in the field of neuroophthalmology. All aspects of patient care are addressed within the journal as well as basic research. Papers covering original research, basic science, clinical and epidemiological studies, reviews and evaluations,

Submit your manuscript here: http://www.dovepress.com/eye-and-brain-journal
Dovepress

guidelines, expert opinion and commentary, case reports and extended reports are welcome. The manuscript management system is completely online and includes a very quick and fair peer-review system, which is all easy to use. Visit http://www.dovepress.com/testimonials.php to read real quotes from published authors. 